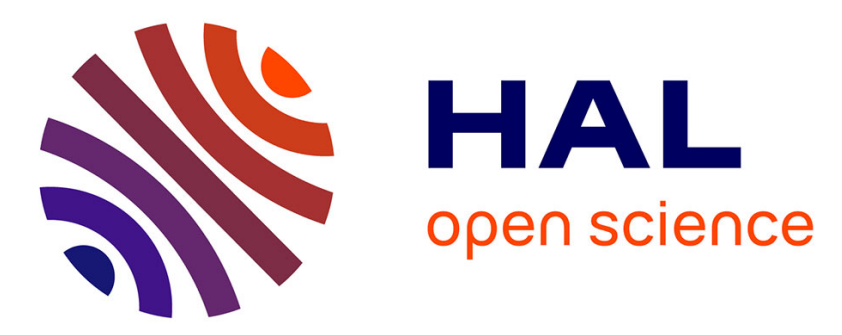

\title{
Compared imbibitions of ordinary and high performance concrete with null or positive water pressure head
}

\author{
Vincent Picandet, Guy Bastian, Abdelhafid Khelidj
}

\section{To cite this version:}

Vincent Picandet, Guy Bastian, Abdelhafid Khelidj. Compared imbibitions of ordinary and high performance concrete with null or positive water pressure head. Cement and Concrete Research, 2008, 38 (6), pp.772-782. 10.1016/j.cemconres.2008.01.014 . hal-01005865

\section{HAL Id: hal-01005865 \\ https://hal.science/hal-01005865}

Submitted on 21 Feb 2017

HAL is a multi-disciplinary open access archive for the deposit and dissemination of scientific research documents, whether they are published or not. The documents may come from teaching and research institutions in France or abroad, or from public or private research centers.
L'archive ouverte pluridisciplinaire HAL, est destinée au dépôt et à la diffusion de documents scientifiques de niveau recherche, publiés ou non, émanant des établissements d'enseignement et de recherche français ou étrangers, des laboratoires publics ou privés. 


\title{
Compared imbibitions of ordinary and high performance concrete with null or positive water pressure head
}

\author{
Vincent Picandet ${ }^{\mathrm{a}}$, Guy Bastian ${ }^{\mathrm{b}}$, Abdelhafid Khelidj ${ }^{\mathrm{b}}$ \\ ${ }^{a}$ Laboratoire de Génie Mécanique et Matériaux (LG2M), Université de Bretagne Sud, BP 92116, 56321 Lorient, France \\ ${ }^{\mathrm{b}}$ Institut de Recherche Génie Civil et Mécanique (GeM), I.U.T., Département Génie Civil, BP 420, 44606 Saint-Nazaire, France
}

\begin{abstract}
A method to simultaneously measure the moisture diffusion coefficient, $D_{\theta}$, of unsaturated concrete, and the saturated concrete hydraulic conductivity, $K_{1}$, was developed for cylindrical specimens placed on a container filled with water that could be maintained at a given hydraulic pressure. Ordinary Portland cement Concrete (OPC) with a moderate and High Performance Concrete (HPC) with a low water to cement ratio were tested. The time dependent distribution of water content in the specimens was measured using a non-intrusive method based on gamma-ray attenuation. The measurements were conducted with varying hydraulic head (positive or null). Boltzmann's transformation was used to analyze the experimental results obtained at different hydraulic pressures and the difference between the null (or atmospheric) and positive pressure results is used to accurately determine $K_{1}$ and also $D_{\theta}$. This paper will present the results obtained using this original method, possible interpretations and future research.
\end{abstract}

Keywords: Durability; Diffusion; Permeability; Concrete; High performance concrete

\section{Introduction}

Civil engineering materials are mostly porous. They can absorb, retain and transfer quantities of water within the liquid and vapor phases. These materials can then be subjected to varied coupled heat and moisture transfers. Depending on the degree of saturation, the independent variables are temperature, water content and suction [1], or even relative humidity of air in the case of hygroscopic materials [2,3]. Precision necessitates mentioning a third variable, the pressure of the gaseous phase (air+water vapor) [4]. However, regarding civil engineering materials, cases for which the consideration of this variable is required are exceptional [5] and have been studied within the context of a comprehensive model [6,7]. The use of these materials and, in particular, the evaluation of their durability, requires a good understanding of the water transfer properties.

The method to estimate the hydraulic conductivity presented here applies to nearly saturated and low permeability materials, $[8,9]$. Moisture diffusion coefficient (isothermal) and hydraulic conductivity (or permeability) are among the essential parameters. The determination of the specimen moisture diffusion coefficient by imbibition, using of the water content profile evolution and the Boltzmann transformation, compose the traditional method, using $[10,11]$.

But, whatever the hydraulic head used to perform the imbibition, due to the unknown water content difference between the total saturated and the capillary saturated state, the hydraulic conductivity of the saturated medium remains difficult to assess with a single test. The purpose of this paper is to present an experimental method to determine accurately both moisture diffusion coefficient and hydraulic conductivity of weakly pervious materials, like Ordinary Portland Concrete (OPC) and, more especially, High Performance Concrete (HPC). It is based on a comparison between two imbibition tests, one at positive 
hydraulic head and the other at null hydraulic head. Moreover, very little experimental data about imbibition and the water permeability of high performance materials is available in the literature.

The distribution over time of water content with height in the specimen during these imbibitions are determined by a non-intrusive method using gamma-ray attenuation. The analysis of the water content profile measurements based on the Boltzmann's transformation makes it possible to assess diffusivity, including for water contents close to saturation, on the one hand, and, simultaneously, the saturation permeability, on the other hand. The theoretical development of this method is described and the analysis of the results achieved is presented.

\section{Theoretical formulation}

\subsection{Terms and hypothesis of the problem}

Hereafter, the hydraulic or water head, $H(\mathrm{~m})$, refers to the total potential and is also called total head $(\mathrm{m})$ in soils literature, while the interstitial water pressure head $h(\mathrm{~m})$, refers to pressure potential or matric potential and is also called matric head (m) in soils literature. More details are given in Section 2.2.1.

Zero and positive water head imbibitions cause disturbances in the water balance, which make it possible to measure the material diffusivity. In this study, only the base of the dry cylindrical specimens is in contact with water. Two imbibition tests are carried out, one at null and the other at positive hydraulic head on both types of concrete (OPC and HPC) in isothermal conditions, $10^{\circ} \mathrm{C}$. A schema of the experimental setup is shown in Fig. 1.

The fundamental difference among imbibition at null hydraulic head and positive hydraulic head is the presence or not of a zone where the material is saturated. In the case of a null or negative hydraulic head pressure, this zone is theoretically nonexistent or negligible [10,11]. With positive head, this zone exists and its height varies with time $[8,12]$. In isothermal

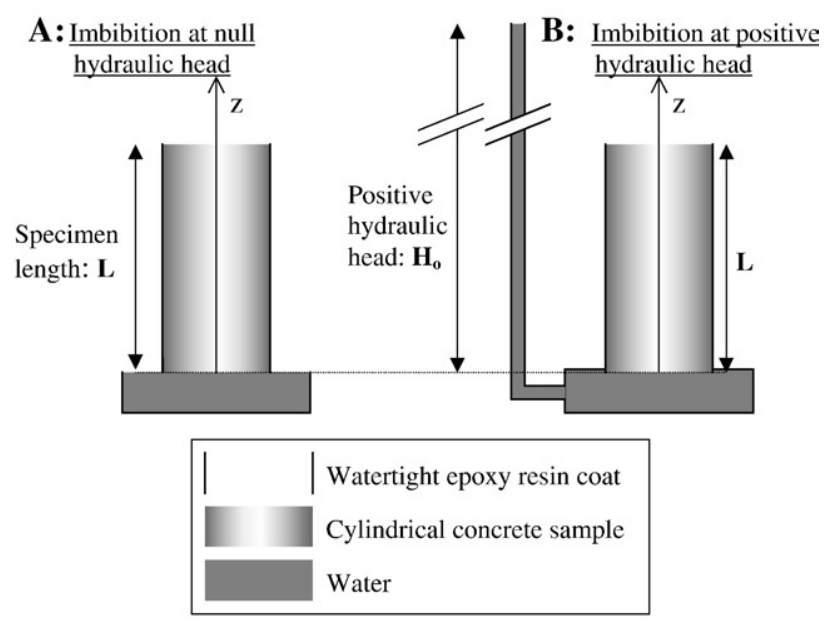

Fig. 1. General diagram of the imbibition at null and positive hydraulic heads. conditions, a general equation of the unsaturated flow is established. Depending on the type of imbibition, the considered mean variable can be the interstitial water pressure head, $h$, or the local water content $\theta$.

The problem discussed here is similar to that of water migration within soils which was analyzed for instance by Philip [13]. However, here the approach is reversed since the objective of this study is to measure the time dependent distribution of the water content inside the specimen and to determine from these measurements the total diffusivity (liquid and vapor phases), $D_{\theta}$, of the unsaturated zone and the hydraulic conductivity, $K_{1}$, of the water saturated material. Measurements are carried out on initially isohydric $0.20 \mathrm{~m}$ tall cylindrical specimens with a water content $\theta_{\mathrm{o}}$ close to zero. The drying procedure for the specimens is described in Section 3.1. In configuration A (see Fig. 1), the test is typical for moisture diffusivity determination. From the instant $t=0$, the base of the specimen is maintained in contact with the free water surface. In configuration $B$, the base of the specimen is maintained in contact with water at a hydraulic head $H_{\mathrm{o}}$ (equal to $10 \mathrm{~m}$ ).

On the assumption that concrete is a rigid and homogeneous porous medium in the studied representative volume and by respecting some definite boundary conditions, profile evolutions during imbibition can be analyzed using the traditional Boltzmann's method to determine the diffusivity $D_{\theta}$ as has been done elsewhere for cement paste or mortar [8,10,14-16]. In addition to the classical imbibition (null hydraulic head), the analysis can also be extended to positive hydraulic head imbibitions, the comparison of which should theoretically lead to the determination of the hydraulic conductivity $K_{1}$ of the studied material.

\subsection{Isothermal water transfer equation}

\subsubsection{Considered variable}

In unsaturated porous media, an equation can be established (for isothermal conditions) using one of the independent variables (volumetric water content $\theta$; suction $\psi$; pressure of the liquid phase $p_{1}$ [17]; hydraulic head or piezometric height $H(\mathrm{~m})$ [18].

If $z$ is the perpendicular height and $h$, the interstitial pressure head, then $H$ is the total hydraulic head: $H=h+z$. If the material is not saturated, the variable $h$ is a function of $\theta$. Due to negative meniscus curvature, the value of $h$ is negative and corresponds to capillary suction, $\psi(\mathrm{m})$, (i.e., $\psi \equiv h)$.

In the case of imbibition, the material water content is increasing at all points inside the specimen during the test. No hysteresis phenomenon has to be considered and a monotonic function, $h=\psi(\theta)$, relating to the unsaturated zones, can be assumed [10].

\subsubsection{Richards' equation}

Many authors, [17-19], have underlined the relevance of the formulation according to the interstitial pressure head $h$, which remains valid for both the saturated media with hydraulic conductivity, $K_{1}$, and the unsaturated media with hydraulic conductivity, $K_{\theta}$, as well as at the limit of both states. 
For a rigid medium, this formulation results in Richards' equation (1931) in the case of a vertical and one-dimensional transfer:

$\frac{\partial h}{\partial t} c_{(h)}=\frac{\partial}{\partial z}\left[K_{\theta}\left(\frac{\partial h}{\partial z}+1\right)\right]$

Where $c_{(h)}$ is the capillary capacity, $\left(\mathrm{m}^{-1}\right)$, defined as $c_{(h)}=$ $\mathrm{d} \theta / \mathrm{d} h$. Using $c_{(h)}$, the relationship between the global hydraulic conductivity $K_{\theta}$ and the global equivalent moisture diffusion coefficient $D_{\theta}$ of material is $D_{\theta}=K_{\theta} / c_{(h)}$. $K_{\theta}$ and $D_{\theta}$ are dependent of either $h$ or $\theta$.

Because the pressure field appears in the solution, Richards' equation can be used to describe the hydrodynamic behavior of both saturated and unsaturated zones. It, therefore, applies to the whole specimen.

The presence of $z$ (gravity effect) in the expression of $H$ is not convenient for the computation of Eq. (1) unless the flow is considered horizontal, which, however, is more difficult to experiment.

For an ordinary mortar, in capillary condensation conditions, i.e., for an intermediate water content $(0.04<\theta<0.08$, ) when $\theta<\theta_{\text {sat }}$, the suction in the capillary condensation zone classically reaches, values on the order of $10^{3} \mathrm{~m}$. For concrete specimens, the gradient due to capillary pressure is much more important than the hydraulic gradient due to gravity, thus: $|\psi|>>z$ leads to consider $\partial h(\theta) / \partial z>>1$ and $h \cong H$.

When $\theta=\theta_{\text {sat }}$, the configuration of the tests is such that $H_{\mathrm{o}}>>L$ (cf. Section 2.1, Fig. 1) and implies $\partial h(\theta) / \partial z>>1$ and $h \cong H$.

Whatever the condition on $\theta$ in the configuration of the tests, Eq. (1) reduces to:

$\frac{\partial h}{\partial t} c_{(h)}=\frac{\partial}{\partial z}\left(K_{\theta} \frac{\partial h}{\partial z}\right)$

\subsection{Boltzmann's transformation}

Boltzmann variable, $u=z / t^{1 / 2}$, can be introduced into Eq. (2). The solution of the equations using Boltzmann's method re- quires conditions so that the medium can be considered to be half-infinite for $z>0$, i.e., when the following initial and boundary conditions are satisfied:

If $t=0, \forall z \geq 0$, (i.e., $u \rightarrow \infty)$, then $\theta=\theta_{\text {o }}$

If $t>0$ and $z=0$, (i.e., $u=0$ ), then $\theta>\theta_{\mathrm{o}}$ and $H=H_{\mathrm{o}}$;

The perpendicular height of the limit of saturation, $z_{\mathrm{h}}$, is conventionally defined as the height to which a rise in the water content is detectable from the initial value $\theta_{\mathrm{o}}$ (see Fig. 2):

If $z>z_{\mathrm{h}}$, then $\theta=\theta_{\mathrm{o}}$.

If $0<z<z_{\mathrm{s}}$, then $\theta>\theta_{\mathrm{o}}$.

$z_{\mathrm{h}}(t)$ can be expressed according to the Boltzmann variable, $u_{\mathrm{W}}(t)$, as: $u_{\mathrm{W}}(t)=z_{\mathrm{h}} / t^{1 / 2}$.

However, Boltzmann's method can be used to process the experimental measurements if $z_{\mathrm{h}}(t)$ is lower than the height of the tested specimen only. For positive hydraulic head imbibitions, the limit between the saturated and the unsaturated zones is located at the height $z_{\mathrm{s}}$ corresponding to the saturation front (see Fig. 2)

If $z>z_{\mathrm{s}}$, then $\theta_{\mathrm{o}} \leq \theta<\theta_{\text {sat }}$.

If $0<z<z_{\mathrm{s}}$, then $\theta=\theta_{\text {sat }}$ : the specimen is locally water saturated.

Similarly, $z_{\mathrm{S}}(t)$ can be expressed according to the Boltzmann variable, $u_{\mathrm{s}}(t)$, as: $u_{\mathrm{s}}(t)=z_{\mathrm{s}} / t^{1 / 2}$.

\subsubsection{Solution of Richards' equation for water saturated zones}

If $z<z_{\mathrm{s}}, c_{(h)}=0, K_{\mathrm{vap}(\theta \mathrm{sat})}$ is null and $K_{1(\theta \text { sat })}$ represents the hydraulic conductivity of the water saturated material, $K_{1}$. Eq. (1) leads to $d^{2} h / \mathrm{d} u^{2}=0$. Using the boundary conditions, the solution of the differential becomes:

$h=H_{\mathrm{o}}\left(1-\frac{u}{u_{\mathrm{s}}}\right)$

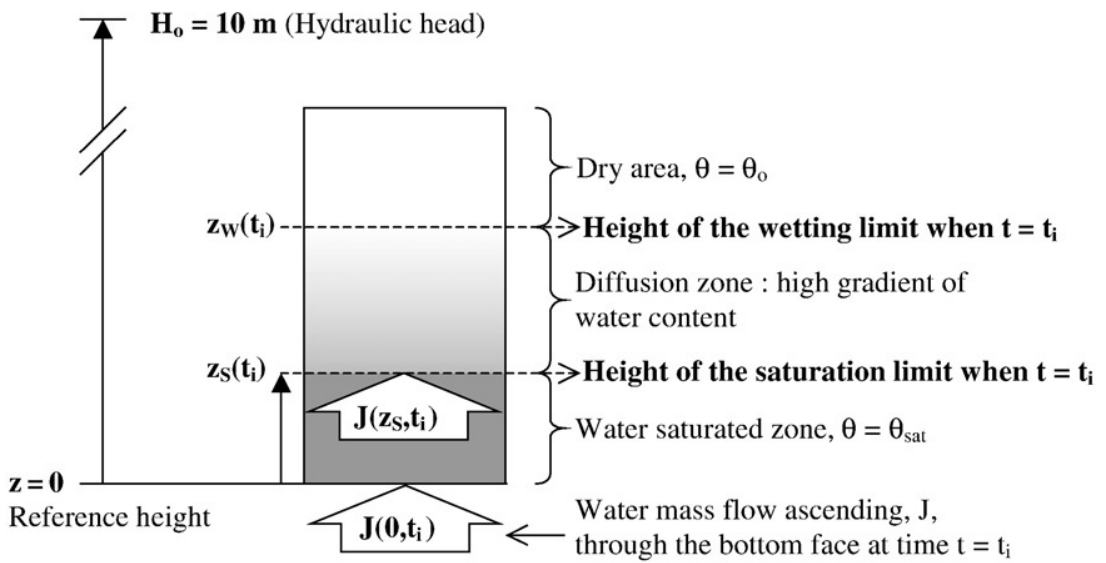

Fig. 2. Diagram of distribution of the water contents and equivalence of water flows inside specimens during imbibition at positive hydraulic head. 
The Boltzmann variable corresponding to $z_{\mathrm{s}}(t), u_{\mathrm{s}}$, is a timeindependent constant. If the gravity effect is neglected, the saturation front progresses according to the square root of time, whatever the hydraulic head of the imbibition [17]. So, for a material imbibition at a given hydraulic head, $u_{\mathrm{s}}$ is theoretically constant.

\subsubsection{Solution of Richards' equation for unsaturated zones}

If $z>z_{\mathrm{s}}$, the interstitial pressure head, $h$, is difficult to achieve experimentally. $h$, inside the specimen, is negative in the unsaturated zone. It depends on $\theta$ according to the suction relationship of the material, $\psi(\theta)$, which is single valued for imbibition. The hypothetical distribution of $h$ within the whole specimen is schematically drawn in Fig. 3.

Eq. (2), with $\theta$ as the main variable, becomes:

$D_{\theta}=-\frac{1}{2 \frac{d \theta}{d u}} \int_{\theta_{\mathrm{o}}}^{\theta} u(\theta) d \theta$

The solution is then classically obtained from the experimental determination of $\theta(u)$. So, the diffusivity can be calculated from a derivative and an area of Boltzmann's curve (see Fig. 4). This curve is determined using a fitting of the experimental data.

\subsection{Water permeability calculation}

\subsubsection{Darcy's law application in saturated zone}

At a given time $t$, the distribution of the interstitial pressure head, $h$, in the saturated zone is a linear function of $z$ while Darcy's law applies. In the configuration of the present tests, $\forall t$, $H_{\mathrm{o}}>>z_{\mathrm{s}}$ is assumed. The equation of the ascending water mass flow at the height $z=0$ then takes the form:

$J_{1}(0, t)=-\rho_{1} K_{1} \frac{H_{\mathrm{o}}}{z_{\mathrm{S}}(t)}$

The specimen increase in mass, $\Delta m_{\mathrm{i}}$, at the moment $t=t_{\mathrm{i}}$ of the imbibition is obtained by integrating the water mass flow during the lapse of time $\left[0 ; t_{\mathrm{i}}\right]$. If the boundary conditions are satisfied, the calculation of the moisture diffusion coefficient can be carried out according to Boltzmann's method. These conditions imply a constant and uniform pressure of the gas

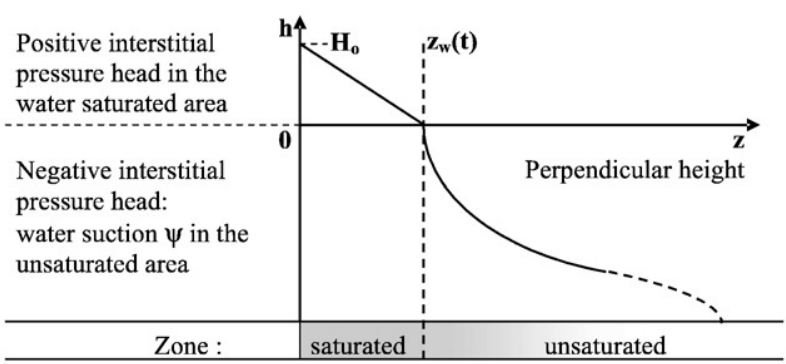

Fig. 3. Variations of $h$ within the specimen during imbibition at positive hydraulic head $H_{\mathrm{o}}$.

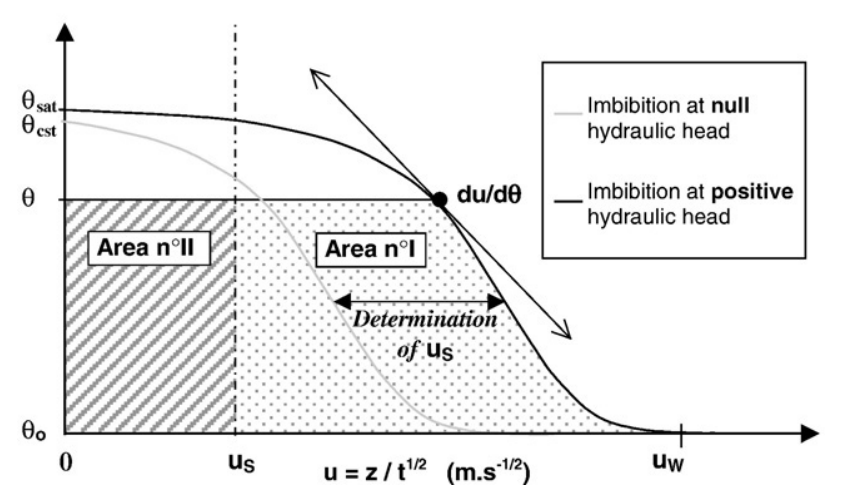

Fig. 4. Evaluation of concrete moisture diffusion coefficient and permeability from the curve $\theta(u)$ relative to imbibitions at null and positive hydraulic heads.

inside the material (atmospheric pressure), a macroscopically homogeneous solid phase, and no chemical reaction during the imbibition. This last condition presupposes that $K_{1}$ remains constant in time and is equal in all points of the specimen. Eq. (5) then becomes:

$\Delta m_{\mathrm{i}}=S \rho_{1} H_{\mathrm{o}} \frac{K_{1}}{u_{\mathrm{s}}} 2 \sqrt{t_{\mathrm{i}}}$

The water volume infiltrated inside the specimens since the beginning of the test $\Delta V_{\mathrm{i}}$ at time $t_{\mathrm{i}}$ is $\Delta V_{\mathrm{i}}=\Delta m_{\mathrm{i}} / \rho_{\mathrm{l}}$. The hydrostatic pressure, at the height $z=0$, is $P_{\mathrm{o}}=\rho_{\mathrm{l}} g H_{\mathrm{o}}$. The water permeability, $k_{\text {water }}\left(\mathrm{m}^{2}\right)$, does not depend on the temperature, but is equivalent to $K_{1} \mu_{1} / \rho_{1} g$ at $10{ }^{\circ} \mathrm{C}$ and can be obtained from:

$k_{\mathrm{water}}=\frac{\mu_{\mathrm{l}}}{2 S P_{\mathrm{o}}} \frac{\Delta V_{\mathrm{i}} u_{\mathrm{s}}}{\sqrt{t_{\mathrm{i}}}}$

In addition, since the water content profiles of the specimen at time $t_{\mathrm{i}}: \theta\left(z, t_{\mathrm{i}}\right)$ are known, the water volume infiltrated inside the specimen $\Delta V_{\mathrm{i}}$ since the beginning is obtained by integrating the water content profile over the specimen length, $L$. When the end of the imbibition is reached (instant $t_{\mathrm{i}}$ ), the infiltrated water volume is checked by weighing the specimen.

\subsubsection{Boltzmann variable of the saturation limit, $u_{s}$}

Several methods to determine $u_{\mathrm{s}}$ are available for the computation of the permeability according to Eq. (7). $u_{\mathrm{s}}$, which represents the water saturation limit is mobile in space, but theoretically constant in Boltzmann's referential system, $\theta=f(u)$. The horizontal curve section $\theta(u)$, where $\theta=\theta_{\text {sat }}$, should apply from $u=0$ to $u=u_{\mathrm{s}}$ when an external pressure is used.

However, it should be noted that $\theta_{\text {sat }}$ represents the total saturation water content. During imbibition at null hydraulic head, the experiments show that, for the lowest values of $u$, the water content never reaches the value $\theta_{\text {sat }}[8,20]$. In this case, the maximal water content should correspond to the capillary saturation moisture content only, $\theta_{\text {cst }}$, (see Fig. 4).

When a positive hydraulic head $H_{\mathrm{o}}>0$ is applied, larger voids are also filled and include more water. The water content then reaches the value $\theta_{\text {sat }}$. 
Theses voids, larger than capillary pores, should account for this result [17]. They are only due to a part of the entrapped air during mixing and casting which is lower than $5 \%$ in concrete mixes used.

The difference between the maximum water content reached with and without external pressure is minor but does not allow the determination of $u_{\mathrm{s}}$ from a single imbibition at positive water head. Even if $\theta_{\text {sat }} \cong \theta_{\text {cst }}$ is considered, the curve shape and the uncertainties of measurements for the points corresponding to water contents close to water/specimen interface make this determination too inaccurate.

In order to evaluate $u_{\mathrm{s}}$ with the best possible accuracy and objectivity, the influence of the positive hydraulic head on the evolution of the water content profiles only is observed. The deviation according to $u$ between the curves relative to imbibition at null and positive hydraulic heads is then measured as shown in Fig. 4.

\subsection{Moisture diffusion coefficient calculation}

The global moisture diffusion coefficient, $D_{\theta}$, can be calculated, for an imbibition without hydraulic head, using the $\theta=f(u)$ relationship and Eq. (4).

For a positive hydraulic head imbibition, the curve $\theta(u)$ reveals a shift equivalent to $u_{\mathrm{s}}$ in comparison to null head. $D_{\theta}$ is then determined from:

$D_{\theta}=u_{\mathrm{s}}\left(\theta-\theta_{\mathrm{o}}\right)-\frac{1}{2} \frac{d u}{d \theta} \int_{\theta_{\mathrm{o}}}^{\theta} u(\theta) d \theta$

$u_{\mathrm{s}}$ being known, $D_{\theta}$ is deduced from the graph $\theta=f(u)$ using the method illustrated in Fig. 4. For a given $\theta$, the derivative of $u(\theta)$ does not change. However, for pressurized imbibitions, the integral of $u(\theta)$ is increased by the value $\left(\theta-\theta_{\mathrm{o}}\right) u_{\mathrm{s}}$ (area $\left.\mathrm{n}^{\circ} \mathrm{II}\right)$. If $u \leq u_{\mathrm{s}}$ then $\theta \geq \theta_{\text {cst }}$ and the capillary pores are water saturated and no moisture diffusivity phenomena occur.

In the case of imbibitions without hydraulic head, the area $\mathrm{n}^{\circ} \mathrm{II}$ does not exist; the total area $\mathrm{n}^{\circ} \mathrm{I}$ (for $\theta=\theta_{\text {cst }}$ ) is called sorptivity, and the value of $u_{\mathrm{W}}$ can be defined as the material penetrability $[17,8]$. The penetrability, $u_{\mathrm{W}}$, represents the expansion speed of the wetting front. The initial water content $\theta_{\mathrm{o}}$ corresponds to $u_{\mathrm{W}}$. Therefore, $\theta_{\mathrm{o}}$ is the lower and the higher limits of the integration range of $u(\theta)$ for the determination of the sorptivity (area $n^{\circ}$ I, see Fig. 4) are $\theta_{o}$ and $\theta_{\text {cst }}$ respectively.

\section{Experimental study}

\subsection{Specimen preparation}

Twenty $110 \times 220-\mathrm{mm}$ cylindrical specimens are prepared from a single batch for each mix. The concrete mixtures are cast in steel molds and compacted using a mechanical vibrator. The mix proportion of each concrete is given in Table 1. The OPC was the concrete used in a national program, so many experimental data are available about it [21]. The average composition of standard mortar used in literature (e.g. $[10,14,8]$ ) is also given as reference.
Table 1

Details of concrete mix proportion

\begin{tabular}{|c|c|c|c|}
\hline \multirow[b]{2}{*}{ Mix ingredients $\left(\mathrm{kg} / \mathrm{m}^{3}\right)$} & \multicolumn{2}{|c|}{ Present study } & \multirow{2}{*}{$\begin{array}{l}\text { Standard } \\
\text { mortar }\end{array}$} \\
\hline & $\mathrm{OPC}$ & $\mathrm{HPC}$ & \\
\hline Aggregate 4-20 mm (OPC), 4-12.5 mm (HPC) & 1193 & 1011 & - \\
\hline Sand $0-5 \mathrm{~mm}(\mathrm{OPC}), 0-4 \mathrm{~mm}(\mathrm{HPC})$ & 744 & 722 & 1500 \\
\hline Cement CPA-CEM I 52.5 & 353 & 400 & 500 \\
\hline Silica fume & - & 40 & - \\
\hline Plasticizer, and filler & - & 79 & - \\
\hline Water/cement ratio & 0.49 & 0.29 & 0.5 \\
\hline Dry apparent density $\left(\mathrm{g} / \mathrm{cm}^{3}\right)$ & 2.34 & 2.33 & 2.07 \\
\hline Total open porosity $(\%)$ & 10.5 & 12.1 & 17 \\
\hline
\end{tabular}

The specimens are stored in a room maintained at $20{ }^{\circ} \mathrm{C}$ with a $95 \%$ relative humidity $(\mathrm{RH})$ for $24 \mathrm{~h}$ after casting, and are cured in water at $20^{\circ} \mathrm{C}$ for 4 weeks. They are then put in a nonventilated drying oven and kept at $60{ }^{\circ} \mathrm{C}$ for 2 days to finish the curing procedure. Finally, they are stored in an air-conditioned room $\left(20^{\circ} \mathrm{C}\right.$ and $\left.\mathrm{RH} 50 \pm 5 \%\right)$.

Before testing, the samples are finally dried for several months up to $105^{\circ} \mathrm{C}$ in a ventilated oven by stages of increasing temperature, one month at $60{ }^{\circ} \mathrm{C}$ and one month at $80{ }^{\circ} \mathrm{C}$, in order to limit the microcracking effect due to strong moisture gradients. Drying duration at $105^{\circ} \mathrm{C}$ over 4 months for the OPC and over 6 months for the HPC allows a quasi complete drying of the specimens. The rate of mass loss among samples is small: less than $0.02 \%$ between two mass measurements separated by a 2-weeks time interval. At the end of the last drying stage, the mass of each sample is regarded as the dry reference $\left(\theta_{\mathrm{o}} \cong 0\right)$. The samples stored in water are considered the water saturated reference $\left(\theta_{\text {sat }}\right)$ and give the total porosity open to water (see Table 1).

\subsection{Water content measurements using gammametric technics}

The gamma-ray attenuation method allows for non-destructive and non-intrusive measurements of the specimen water content profiles according to the vertical axis $(z)$ during imbibition.

This scanning technique makes it possible to determine local water contents within specimens during moisture transfer processes. Many authors use the transmission or attenuation analysis of the radiation beam through mortar specimens for different imbibition configurations (at various temperatures [10], at negative hydraulic head [14], or at null and positive hydraulic head [8]). Other non-intrusive scanning techniques using nuclear magnetic resonance (NMR) imaging have been also developed $[15,16]$.

Our gamma-ray device has been developed within the laboratory for sedimentation-consolidation studies. It can be used, among other things, for automated measurements specifically computing for the determination of the water content profiles during the tests [20].

The tests are carried out on (OC), and (HPC) isohydric specimens (i.e. $\theta=\theta_{\mathrm{o}} \cong 0$ in the whole specimen). Eight specimens are tested here, two OPC and HPC specimens for each configuration (null or positive hydraulic head: $H_{\mathrm{o}}=10 \mathrm{~m}$ ). Given the heterogeneity of materials like concrete, a dry density profile 


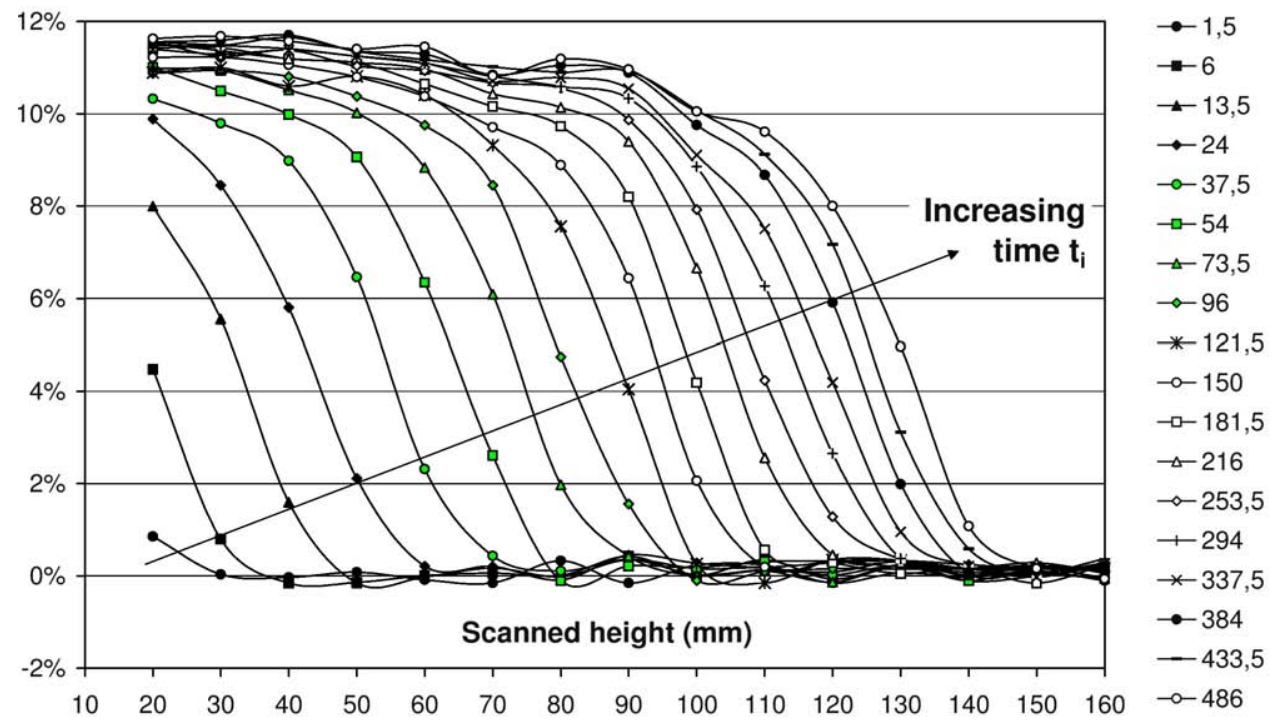

Fig. 5. Volumetric water content evolution for each measured scanning-dimensions of the OPC specimen during imbibition without hydraulic head. (One of every three scan results is shown).

specimen is carried out before each test and is used as a reference for the calculation of the water content profiles during imbibition.

Fig. 5 shows the water content changes within an OPC specimen. As regards HPC, the water content evolution is much slower. For more accuracy and a better consideration of these evolutions, the distance between each measuring points is then reduced by half.

In the present configurations, the density measurement accuracy is approximately $\pm 0.001 \mathrm{~g} / \mathrm{cm}^{3}$. Volumetric water content calculations then agree within $\pm 2 \mathrm{ml} / 1$ (i.e., $0.2 \%$ ). For each measuring position, a wire position sensor calculates the precise scanning height, $z( \pm 10 \mu \mathrm{m})$.
3.3. Observation of the results in the Boltzmann's referential $\theta=f(u)$

Fig. 6 presents the scaled water contents for the data shown in Fig. 5.

\subsubsection{Definition of a standard profile $\theta(u)$}

To assess the transfer parameters from the $\theta(u)$ data, it is assumed that, beyond the heterogeneity effects, it is possible to conduct a global characterization of a given specimen using a mean coefficient $D_{\theta}$ dependent on the water content only. From this point of view and compared to other experimental data,

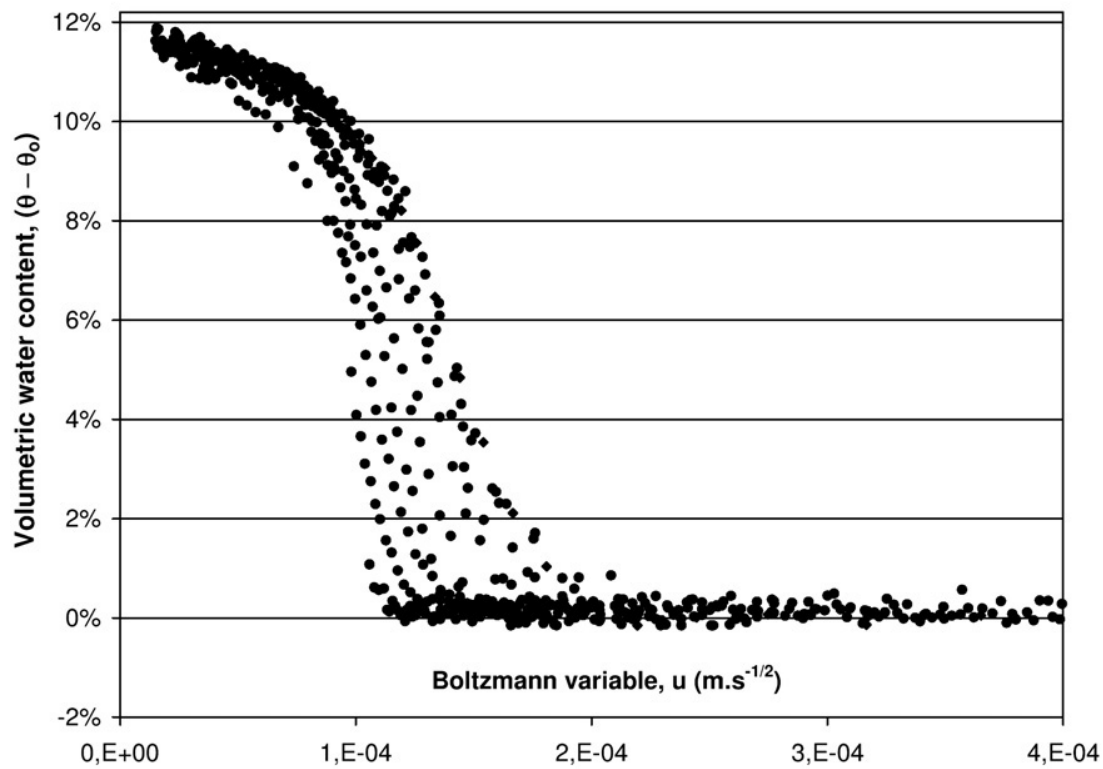

Fig. 6. Volumetric water contents in Boltzmann's referential, imbibition of an OPC specimen at null hydraulic head. 


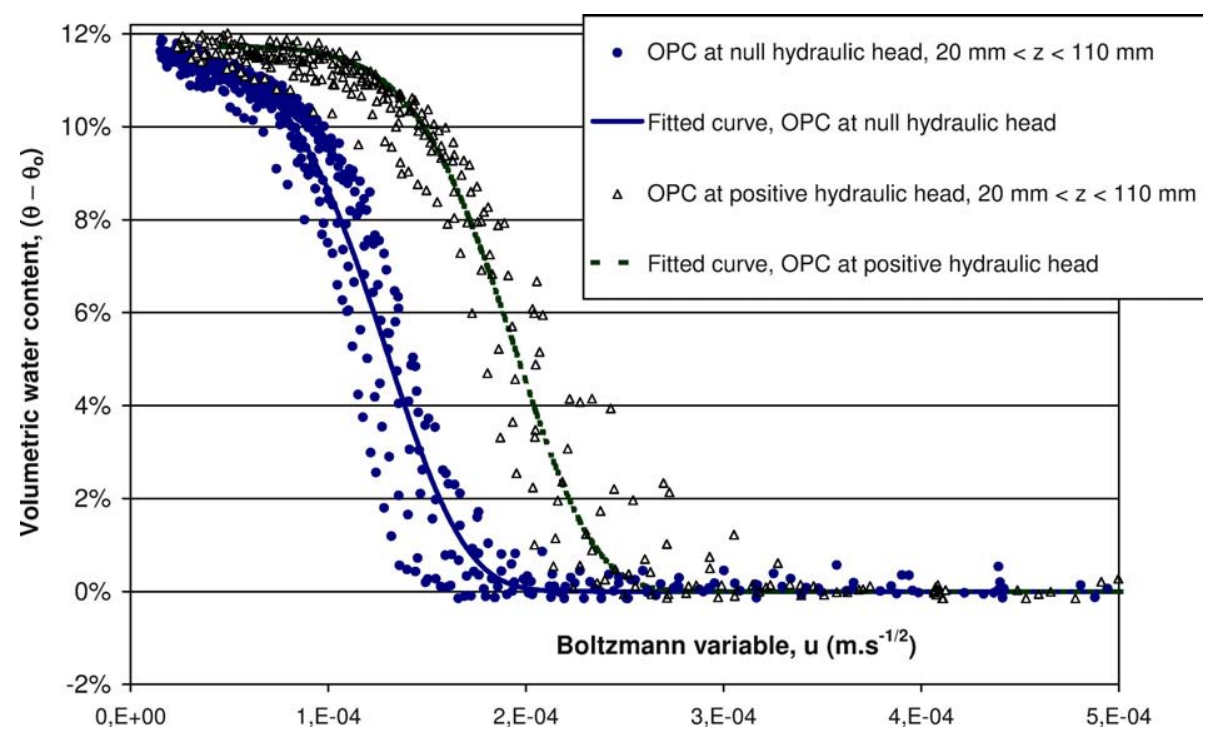

Fig. 7. Adjustment of standard profiles for OPC specimens during imbibition at null and positive hydraulic heads.

Boltzmann's referential law $\theta=f(u)$ gives a satisfactory representation of all the experimental data relating to one test.

In order to adjust a time function which can be used whatever the specimen, considering the less scattered plots is necessary.

Afterwards, the upper sections, for which, at a given height and after a given time, water contents are less than $80 \%$ of the saturation water content $\theta_{\text {sat, }}$ are not taken into account for the determination of the standard profile $\theta(u)$. Subsequently, only the water contents varying between $20 \mathrm{~mm}$ and $110 \mathrm{~mm}$ for OC, and between $20 \mathrm{~mm}$ and $60 \mathrm{~mm}$ for HPC are considered. They roughly correspond to the measurements obtained after 9 or 10 consecutive scanning positions.

\subsubsection{Adjustment of the standard profile $\theta(u)$}

The standard profile analysis of each specimen is carried out by fitting an analytical function $\theta_{\text {th }}(u)$ to the measurements selected to describe the standard profile. It is drawn in the solid curve in Figs. 7 and 8 . The function $\theta_{\text {th }}(u)$, defined by Eq. (9), is chosen for its general shape and its null derivative when $u$ tends to infinity.

If $u<d$ then $\theta_{\text {th }}(u)=a$, else $\theta_{\text {th }}(u)=a \exp \left[-b(u-d)^{c}\right]$

$\theta_{\mathrm{th}}(u)$ is fitted to the experimental data using ordinary least squares analysis. The adjustment of the four parameters $a, b, c, d$ gives $a=\theta_{\text {sat }}$. In order to accelerate convergence, only the three parameters $b, c, d$, are afterwards systematically adjusted.

For a given concrete, the curves $\theta_{\text {th }}(u)$ are theoretically identical but are skewed by the constant $u_{\mathrm{s}}$ according to the $u$-axis. So $\theta_{\mathrm{th}}(u)$ is adjusted from the results achieved for one concrete type only, but for both configurations (with and without positive hydraulic head) and considering the additional parameter $u_{\mathrm{s}}$ (i.e. the shift between both series of results).

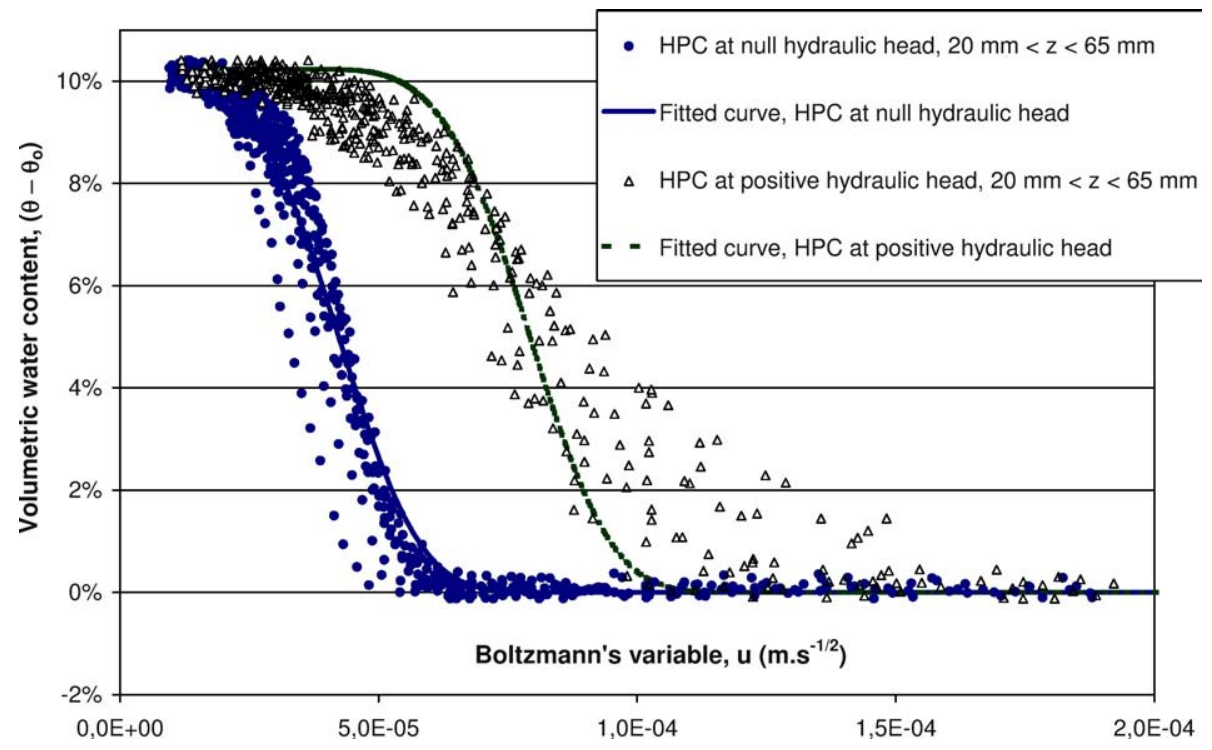

Fig. 8. Adjustment of standard profiles for HPC specimens during imbibition at null and positive hydraulic heads. 
Table 2

Penetrability and sorptivity values $\left(\mu \mathrm{m} \mathrm{s}^{-1 / 2}\right)$

\begin{tabular}{lrrlll}
\hline & \multicolumn{2}{l}{ Present study } & & $\begin{array}{l}\text { Mortar at } \\
10^{\circ} \mathrm{C}[8]\end{array}$ & $\begin{array}{l}\text { Mortar at } \\
20{ }^{\circ} \mathrm{C}[10]\end{array}$ \\
\cline { 2 - 3 } & OPC & HPC & & 214 & 166 \\
\hline Penetrability, $u_{\mathrm{W}}$ & 200 & 90 & & 22 & 19 \\
Sorptivity & 15 & 5 & & 22 & - \\
$u_{s}$, if $H_{\mathrm{o}}=10 \mathrm{~m}$ & 63 & 36 & & - & \\
\hline
\end{tabular}

The fitted curves in Figs. 7 and 8 show that HPC sorptivity is lower than that of OC. The theoretical translation between the profiles of specimens in imbibition at null and positive hydraulic head appears less correct for HPC than for OPC specimens.

\subsection{Moisture diffusion coefficient assessment}

For a given water content, moisture diffusion coefficient assessment requires to determine the derivative $\mathrm{d} u / \mathrm{d} \theta$ and the sorptivity, i.e., area ${ }^{\circ} \mathrm{I}$ in Fig. 4.

The function $\theta_{\text {th }}$ is used to calculate the derivative of the standard profile $\theta(u)$ of one test. We then obtain:

If $u<d$ then $d \theta_{\text {th }} / d u=0$ else $\frac{d \theta_{\text {th }}}{d u}=-\left[b c(u-d)^{c-1}\right] \theta_{\text {th }}(u)$

Using this result in Eq. (8) we obtain the moisture diffusion coefficient (Section 2.5). The function $\theta_{\mathrm{th}}(u)$ is used for the determination of the mean value of $u_{\mathrm{s}}$ (see Table 2) during the test, and for the permeability calculation using Eq. (7) only.

The determination of the sorptivity depends on the $u(\theta)$ integral initial starting point, i.e., $u_{\mathrm{W}}-u_{\mathrm{s}}$ is equal to the penetrability. The experimental determination of this value is very difficult. The integral value of the reciprocal function $u(\theta)$ is given by integration of the standard profile using the experimental plots and a trapezoid method. When the hydraulic head is positive, area ${ }^{\circ} \mathrm{II}$ (see Fig. 4) is deducted by considering the mean value of $u_{\mathrm{s}} . u_{\mathrm{s}}$, the penetrability-mean values, $u_{\mathrm{W}}$, and the calculated sorptivity are presented in Table 2.
Fig. 9 presents the mean moisture diffusion coefficient values calculated for the four studied cases. The comparison between the different curves, $D_{\theta}(\theta)$, obtained confirms that the diffusivity of HPC is lower than that of OC. Despite the deduction of area $\mathrm{n}^{\circ} \mathrm{I}$, the moisture diffusivities calculated for the pressurized imbibitions are slightly higher than those calculated at a null hydraulic head. This variation can be explained by the observed differences between the fitted function and the experimental data obtained for each case.

\subsection{Water permeability determination}

The water volume $\Delta V_{\mathrm{i}}$ infiltrated into the specimen at the time $t_{\mathrm{i}}$ is determined from Eq. (5). First, the water used for the tests is stored in the air-conditioned experimental room $(10 \pm$ $1{ }^{\circ} \mathrm{C}$ ) in order to get thermal and partial pressure equilibria. The dynamic viscosity of the water is then assumed equal to $1.3110^{-3} \mathrm{~Pa}$ s. The average water permeability, $k_{\mathrm{w}}$, during the interval of time $\left[0 ; t_{\mathrm{i}}\right]$ is calculated using Eq. (6) and is presented in Fig. 10 for both concrete types.

The ratio of the water volume $\Delta V_{\mathrm{i}}$ to the square root of time $t_{\mathrm{i}}\left(\Delta V_{\mathrm{i}} / t_{\mathrm{i}}^{1 / 2}\right)$ is theoretically constant, but, this ratio tends to decrease with time. The horizontal shift observed in Fig. 6 is least at later times (small $u$ ), so we observe less $\Delta V_{\mathrm{i}}$ at longer test periods, and, hence, slightly lower permeability. Consequently, if $u_{1}$ and $u_{\mathrm{s}}$ are constant, the permeability seems to decrease during the imbibition test (see Fig. 10).

\subsection{Short comparative study of the results obtained}

\subsubsection{Moisture diffusivity}

The moisture diffusion coefficient is difficult to estimate. It is strongly dependent on the determination method: from the vapor permeability measurement (cup method) [22,23], from the imbibition test $[8,10,14,20]$, from hygric shocks [2].

For the same concrete, called OC, a factor higher of 100 can be observed between $D_{\theta}$ determined using the first method

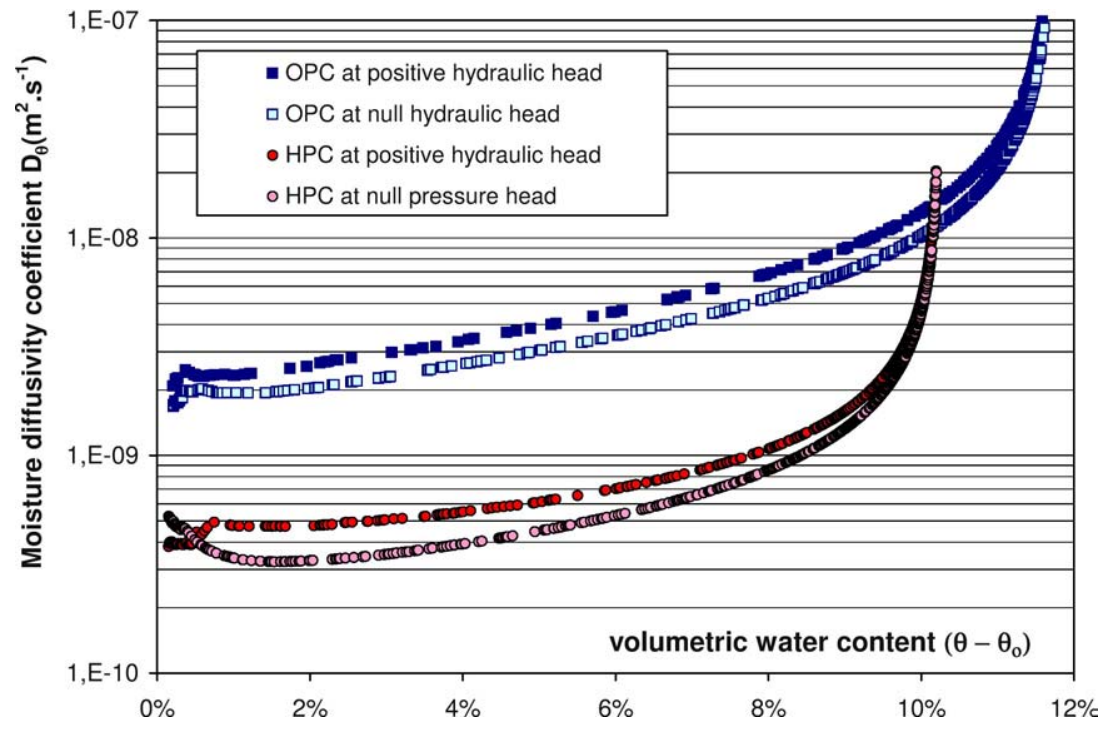

Fig. 9. Moisture diffusion coefficient, $D_{\theta}$, of the tested specimens. 


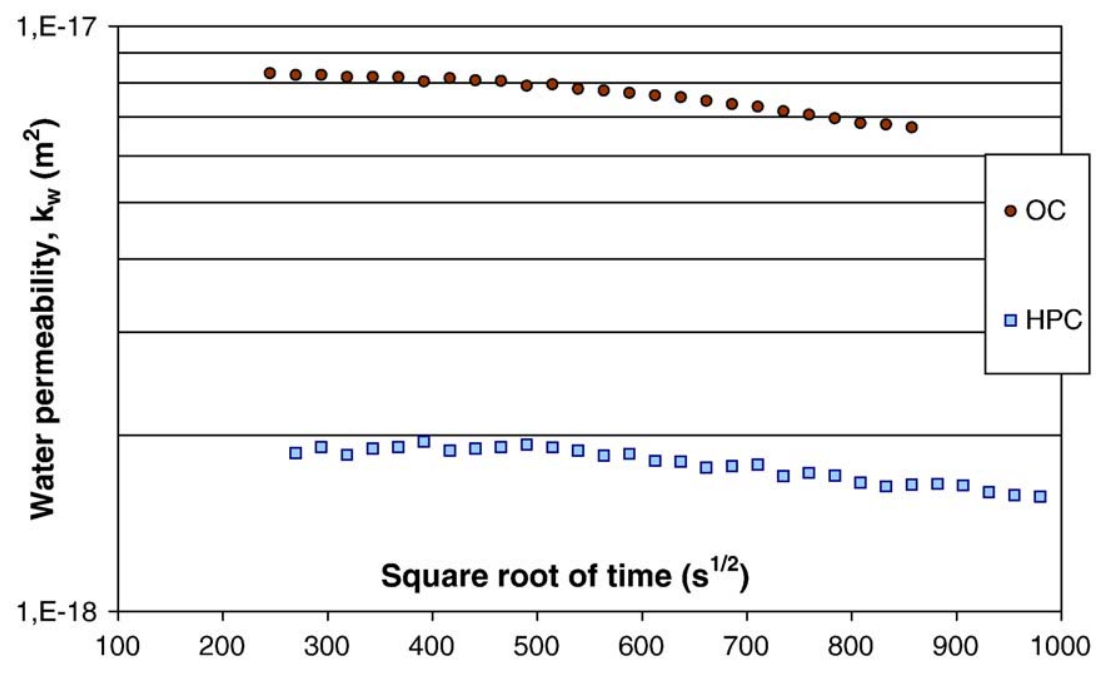

Fig. 10. Permeability of the tested specimens during imbibition at positive hydraulic head.

(cup method) which gives $D_{\theta} \cong 10^{-11} \mathrm{~m}^{2} \mathrm{~s}^{-1}$ and the other ones which give $D_{\theta} \cong 10^{-9} \mathrm{~m}^{2} \mathrm{~s}^{-1}$. This considerable variation is underlined by many authors $[11,22]$. Our results are compared with those carried out on a OPC slab during the drying process. So, this study confirms that dynamic methods give similar results in both cases: drying and imbibition.

The moisture diffusion coefficient values of the studied concrete are slightly higher than those obtained on mortars at identical temperatures [8] or at $20^{\circ} \mathrm{C}[10]$. As shown in Table 2, the measured OPC penetrability is closed to those obtained on mortar. Also, concerning HPC, the penetrability results correspond to the values obtained in other study with high performance mortars containing silica fume [16].

It should be noted that the presence of coarse aggregates inside specimens makes a decrease in the global porosity of material (see Table 1). However, it appears to have a minor effect on sorptivity value and finally on $D_{\theta}$ values.

\subsubsection{Permeability}

The permeability values of ordinary concrete vary a lot because of the different mixtures used. Theoretically, the permeability $\mathrm{k}\left(\mathrm{m}^{2}\right)$ of a fully saturated media of a given percolating fluid does not depend on the type of fluid. The intrinsic gas permeability has been measured in a parallel study conducted using the same concrete batches [24]. It should be noted that the gas permeability of concrete is strongly dependent on its average water content (or gas saturation of the medium), however complete drying of concrete cannot be achieved. The OPC and HPC water permeabilities deduced from this study are consistent with the gas permeabilities measured after moderate drying of the materials, i.e. for a saturation degree close to $11 \%$ for both types of concrete [20]. The same difference is observed: the water and gas permeabilities of HPC are both approximately 10 times lower than those of OC. It should be noted that comparison between gas and water permeability of concrete is only valid for dried concrete. In our case a single drying cycle was applied.

The practical reason for these measurements is to predict the durability of exposed concrete on building or structure surfaces, which is dried to a depth of a few centimeters. In such cases, the transfer properties of dried concrete have to be considered. This is also particularly important for making conservative predictions, since $k$ may rise after drying [25], due to the induced change in microstructure. Little experimental data is available in the literature regarding the water permeability of undried low water to cement ratio concrete or HPC [23,26]. For this type of material, the values are obtained from measurements at constant and large pressure gradients [27]. Some studies using a triaxial cell achieve lower permeability values ranging between $10^{-12}$ and $10^{-16} \mathrm{~m} / \mathrm{s}$ (i.e. between $10^{-19}$ and $10^{-23} \mathrm{~m}^{2}$ ) [28]. These values, however, were obtained from very weak output flows. Generally, concrete water permeability measurements using a traditional measurement method, (i.e. measurement of the flow under constant water pressure gradient), are difficult to perform and the results obtained are much debated [29]. Recently, some new dynamic methods considering both mechanical and transfer properties were developed to measure the water permeability of saturated concrete which has never been dried and have led to values ranging between $10^{-19}$ and $10^{-21} \mathrm{~m}^{2}$ [25,30]. It should be noted that in the present study, a single drying cycle was first applied to each sample and has probably made the permeability risen by two orders of magnitude [25]. Therefore, the presented results seem to be consistent with the current literature. The drying procedure was the same for each specimen and the described permeability measurement method gives values higher than $10^{-18} \mathrm{~m}^{2}$ for both HPC and OC, whose measuring repeatability is satisfactory.

Our alternative measurements method gives water permeability values higher than $10^{-18} \mathrm{~m}^{2}$ for both HPC and OC, whose measuring repeatability is satisfactory. The tests performed over long periods allow to observe and analyze very weak flows of percolating water. Then, inertial effects are avoid and the water/cement matrix interactions should be more limited.

\section{Conclusion}

This study presents an alternative method to assess the water permeability of heterogeneous hygroscopic materials. It is based 
on a simultaneous analysis of the water content evolution during imbibition at null and positive hydraulic heads, and the use of Boltzmann's transformation.

From a single imbibition, the traditional method allows the determination of moisture diffusivity only. To assess accurately the water permeability of the saturated specimen, the deviation, $u_{\mathrm{s}}$, between the curves $\theta(u)$ relative to imbibitions at different hydraulic heads must be evaluated.

Measurements are carried out over longer periods to obtain parameter historical evolutions and better experimental accuracy. By restricting data processing to a limited zone near the wetting specimen surface (section below $110 \mathrm{~mm}$ ), the standard profile $\theta(u)$ of each test configuration has been characterized. The analysis leads to moisture diffusion coefficients in accordance with those given in the literature regarding other cement composed material like mortar. As supposed, the moisture diffusivity is lower for the HPC than for the OPC.

As many experimental studies of cement based materials reveal, a slight decrease in the water permeability appears with time. The values obtained here, indeed, are similar to the intrinsic gas permeability measurements carried out on the specimens made of the same concrete batches.

This original method makes it possible to achieve the water permeability measurement during imbibition of weakly pervious hygroscopic materials (i.e., lower than $10^{-17} \mathrm{~m}^{2}$ ) like OPC and especially HPC. Moreover, the imbibitions at positive or null hydraulic head allow to characterize the hydrodynamic behavior of both water saturated and unsaturated zones and make this experimental method suitable for the study of the concrete durability.

\section{Nomenclature}

\begin{tabular}{|c|c|c|}
\hline$c_{(h)}$ & Capillary capacity & $\mathrm{m}^{-1}$ \\
\hline$D_{\theta}$ & Global moisture diffusion coefficient & $\mathrm{m}^{2} \cdot \mathrm{s}^{-1}$ \\
\hline$g$ & Gravity constant & $\mathrm{m} \mathrm{s}^{-2}$ \\
\hline$H$ & Total hydraulic head (i.e.: total potential) & $\mathrm{m}$ \\
\hline$h$ & Interstitial water pressure head (i.e: pressure potential) & $\mathrm{m}$ \\
\hline$J$ & Mass flux per unit surface & $\mathrm{kg} \mathrm{m}^{-2} \mathrm{~s}^{-1}$ \\
\hline$K_{1}$ & Hydraulic conductivity (saturated medium) & $\mathrm{m} \mathrm{s}^{-1}$ \\
\hline$K_{\theta}$ & $\begin{array}{l}\text { Global hydraulic conductivity of unsaturated medium } \\
\left(K_{1(\theta)}+K_{\operatorname{vap}(\theta)}\right)\end{array}$ & $\mathrm{m} \mathrm{s}^{-1}$ \\
\hline$k_{\mathrm{w}}$ & Water permeability $\left(K_{1} \mu_{1} / \rho_{1} g\right)$ & $\mathrm{m}^{2}$ \\
\hline$P_{\mathrm{o}}$ & Hydrostatic applied pressure $\left(\rho_{1} g H_{\mathrm{o}}\right)$ & $\mathrm{Pa}$ \\
\hline$S$ & Specimen section & $\mathrm{m}^{2}$ \\
\hline$t$ & Time & $\mathrm{S}$ \\
\hline$u$ & Boltzmann variable & $\mathrm{m} \mathrm{s}^{-1 / 2}$ \\
\hline$u_{\mathrm{s}}, u_{\mathrm{w}}$ & $\begin{array}{l}\text { Boltzmann variable at the limit of saturation }\left(z_{\mathrm{s}} t^{-1 / 2}\right) \text {, } \\
\text { at the wetting limit }\left(z_{\mathrm{h}} t^{-1 / 2}\right)\end{array}$ & $\mathrm{m} \mathrm{s}^{-1 / 2}$ \\
\hline$z$ & Perpendicular height & $\mathrm{m}$ \\
\hline$z_{\mathrm{s}}, z_{\mathrm{W}}$ & $\begin{array}{l}\text { Perpendicular height of the limit of saturation, of the } \\
\text { wetting limit }\end{array}$ & $\mathrm{m}$ \\
\hline$\Delta m$ & Masse gain of the specimen during imbibition & $\mathrm{kg}$ \\
\hline$\Delta V$ & Volume of infiltrated water & $\mathrm{m}^{3}$ \\
\hline$\mu_{1}$ & Dynamic viscosity of water at $10^{\circ} \mathrm{C}$ & $\mathrm{Pa} \mathrm{s}$ \\
\hline$\rho_{1}$ & Water density & $\mathrm{kg} \mathrm{m}^{-3}$ \\
\hline$\theta$ & $\begin{array}{l}\text { Local volumetric water content } \\
\text { (for a given height) }\end{array}$ & - \\
\hline$\theta_{\mathrm{o}}$ & Initial water content (at time $t=0$ ) & - \\
\hline$\theta_{\text {sat }}$ & Total saturation water content & - \\
\hline$\theta_{\text {cst }}$ & Capillary saturation water content & - \\
\hline$\psi$ & $\begin{array}{l}\text { Capillary suction or capillary pressure head (negative } \\
\text { meters of water head) }\end{array}$ & $\mathrm{m}$ \\
\hline
\end{tabular}

\section{Acknowledgments}

The authors would like to thank Jean-François Daïan (LTHE, UJF Grenoble, France) and Kenneth A. Snyder (NIST, Gaithersburg Maryland, USA) for useful discussions and their fruitful comments.

\section{References}

[1] P. Crausse, J.-P. Laurent, B. Perrin, Influence des phénomènes d'hystérésis sur les propriétés hydriques de matériaux poreux, Revue Générale de Thermique 35 (1996) 95-106.

[2] G. Bastian, Détermination dynamique des paramètres des transferts couplés de chaleur et d'humidité au sein d'un mortier en régime hygroscopique, Thèse d'Etat, Université de Nantes - E.N.S.M., France, (1989).

[3] G. Bastian, Heat and moisture transfer in capillary-porous bodies. Some experimental methods of investigation, Drying Technologies (special issue on drying research in France) 15 (9) (1997) 2145-2164.

[4] C. Moyne, Transferts couplés chaleur-masse lors du séchage: prise en compte du mouvement de la phase gazeuse. Thèse d'Etat, INPL, Nancy, France, (1987).

[5] P. Kalifa, F.-D. Mennoteau, Mesures de pression, température et perte en masse dans les bétons à hautes températures, Cahiers du CSTB, Etudes et Recherches 3154 (402) (1999).

[6] V. Baroghel-Bouny, M. Mainguy, T. Lassabatere, O. Coussy, Characterization and identification of equilibrium and transfer moisture properties for ordinary and high-performance cementitious materials, Cement and Concrete Research 29 (1999) 1225-1238.

[7] E. Samson, J. Marchand, K.A. Snyder, J.J. Beaudoin, Modeling ion and fluid transport in unsaturated cement systems in isothermal conditions, Cement and Concrete Research 35 (2005) 141-153.

[8] N. Aouaïssia-Abdallah, Messure dynamique des paramètres du transfert isotherme d'humidité dans un mortier, PhD. dissertation, Université de Nantes et école centrale de Nantes, France, (1997).

[9] N. Aouaïssia-Abdallah, G. Bastian, Détermination dynamique par centrifugation des paramètres du transfert isotherme d'humidité dans un matériau poreux proche de la saturation, Matériaux et Constructions 31 (1998) 588-594.

[10] J.-F. Daïan, Processus de condensation et de transfert d'eau dans un matériau méso et macroporeux. Etude expérimentale du mortier de ciment, Thèse d'Etat, INPG, Grenoble, France, (1986)

[11] B. Perrin, V. Baroghel-Bouny, L. Chemloul, Méthodes de détermination de la diffusivité hydrique de pâtes de ciment durcies, Matériaux de Construction 31 (1998) 235-241.

[12] J.-F. Daïan, Personal communication, (2000).

[13] J.R. Philip, The theory of infiltration: 1 . The infiltration equation and its solution, Soil Science 83 (1957) 345-357.

[14] J. A. Bellini Da Cunha Neto, Transport d'humidité en matériaux poreux en présence d'un gradient de température. Caractérisation expérimentale d'un béton cellulaire. PhD thesis, Joseph Fournier, Grenoble, France, 1992.

[15] R.J. Gummerson, C. Hall, W.D. Hoff, R. Hawkes, G.N. Holland, W.S. Moore, Unsaturated water flow within porous materials observed by NMR imaging, Nature 281 (6) (1979) 56-58.

[16] H. Hazrati, L. Pel, J. Marchand, K. Kopinga, M. Pigeon, Determination of isothermal unsaturated capillary flow in high performance cement mortars by NMR imaging, Materials and Structures 35 (2002) 614-622.

[17] J. Bear, Dynamics of Fluids in Porous Media, American Elsevier publishing company, New York, 1972.

[18] A. Musy, M. Soutter, Physique du sol, Presses polytechniques et Universitaires Romandes, Lausanne, 1991.

[19] M. Vauclin, R. Haverkamp, G. Vachaud, Résolution numérique d'une équation de diffusion linéaire, application à l'infiltration de l'eau dans les sols non saturés, Presses universitaires de Grenoble, 1979.

[20] V. Picandet, Influence d'un endommagement mécanique sur la perméabilité et sur la diffusivité hydrique des bétons. PhD thesis, Université de Nantes, France, (2001).

[21] V. Baroghel-Bouny, Caractérisation des pâtes de ciment et des bétons; méthodes, analyse, interprétations, Edition du Laboratoire Central des Ponts et Chaussées, Paris, 1994. 
[22] A. Khelidj, V. Baroghel-Bouny, G. Bastian, J. Godin, G. Villain, Détermination expérimentale des gradients résultant d'une interaction hydratation-séchage dans une dalle en béton, Thème OA 9 du LCPC, Rapport final, 2000.

[23] M. Jooss, H.W. Reinhardt, Permeability and diffusivity of concrete as function of temperature, Cement and Concrete Research 32 (2002) 1497-1504.

[24] V. Picandet, A. Khelidj, G. Bastian, Effect of axial compressive damage on gas permeability of ordinary and high performance concrete, Cement and Concrete Research 31 (2001) 1525-1532.

[25] G.W. Scherer, J.J. Valenza, G. Simmons, New methods to measure liquid permeability in porous materials, Cement and Concrete Research 37 (2007) 386-397.
[26] N. Hearn, R.D. Hooton, R.H. Mills, Pore Structure and Permeability, Significance of Tests and Properties of Concrete and Concrete Making Materials, ASTM Publication, 1994, pp. 240-262.

[27] D. Whiting, Permeability of Concrete, ACI SP-108, 1988, pp. 195-220.

[28] A.S. El-Dieb, R.D. Hooton, Water-permeability measurement of high performance concrete using a high-pressure triaxial cell, Cement and Concrete Research 25 (6) (1995) 1199-1208.

[29] N. Hearn, Effect of shrinkage and load-induced cracking on water permeability of concrete, ACI Materials Journal 96 (2) (1999) 234-241.

[30] Z.C. Grasley, G.W. Scherer, D.A. Lange, J.J. Valenza, Dynamic pressurization method for measuring permeability and modulus: II. Cementitious materials, Materials and Structures 40 (2007) 711-721. 